\title{
LA VISIÓN AÉREA Y LOS IMAGINARIOS GEOGRÁFICOS: UN ENSAYO DE APROXIMACIÓN A UN COMPLEJO UNIVERSO VISUAL
}

- VERONICA HOLLMAN

Resumem: La convergencia de una creciente producción de imágenes aéreas y de una mayar circulación explica que la visión aérea se extienda a públicas cada vez más amplios y diversas. Las imágenes aéreas así como la experiencia de volar y ver de manera directa desde el aire ya farman parte de nuestra cultura visual y participan en la configuración de imaginarios gengráficos. Resulta pertinente reflexionar sobre las posibles aproximaciones a un universo tan vasto de imágenes que tanto desde su producción como desde su arquitectura visual se construyen como lo real. Para ello nos valdremas de los aportes del histariador del arte George Didí-Huberman y de una compasición de imágenes aéreas del artista estadaunidense Jash Begley.

Palabras clave: Visión aérea; Imágenes aéreas; Tecnologías de visualización aérea; Imaginarios gengráficas; Compasición.

Imágenes aéreas y cultura visual

Las imágenes aéreas también se han vuelto ubicuas: cada vez es más frecuente que los ojos (de expertos y legos) encuentren imágenes de la superficie de la Tierra obtenidas desde el aire en soportes tan diversos como libros, folletos turísticos, publicidades, películas, documentales, exposiciones artísticas, las 
pantallas de las computadoras y de los teléfonos inteligentes. Cierto es que, en los últimos cien años, el relevamiento exhaustivo de la superficie terrestre desde el aire y la producción de registros visuales para plasmar esa perspectiva visual no ha cesado de ampliar su cobertura geográfica y temporal en términos cuantitativos y cualitativos. Tan solo el archivo visual del programa Landsat $^{1}$, uno de los setenta $y$ tres programas de observación satelital de la Tierra, contaba con más de 5,5 millones de imágenes en enero del año 2015 (Wulder et al, 2016). En tanto que en sus 27 años de vida el programa de observación satelital francés SPOT produjo 30 millones de imágenes de la Tierra. La producción de imágenes aéreas se ha incrementado todavía más en los últimos veinte años con el desarrollo y la disminución de los costos de algunos dispositivos de movilidad y captura de la información aérea, particularmente de los vehículos aéreos no tripulados -más conocidos como drones. Una estimación realizada por una de las empresas creadoras de un drone (DJI Mavi) puede servirnos como indicador de la dimensión del universo visual al cual nos referimos: en los últimos 12 meses fueron tomadas 560000000 imágenes aéreas (fotografías $\mathrm{y}$ videos) tan solo en esa plataforma.
Sin embargo, probablemente la novedad de este período consista en la convergencia de una creciente producción y circulación de las imágenes aéreas. Por un lado, una parte cada vez más importante de los archivos visuales de algunos de estos programas de observación terrestre se ha declarado de dominio público $\mathrm{y}$ esto sin duda ha promovido una mayor circulación de estas imágenes. Así por ejemplo, en el año 2008 el United States Geological Survey (USGS) declaró de acceso libre y público las imágenes del programa Landsat $7 \mathrm{y}$, un año después, la totalidad de imágenes Landsat de su acervo². Según datos oficiales de este mismo organismo en marzo del año 2017, se descargaron 56 millones de escenas de su archivo visual ${ }^{3}$. Cabe destacar que gran parte de las imágenes utilizadas en Google Earth provienen de este catálogo de imágenes aéreas. Francia también anunció en el año 2014 el libre acceso a las imágenes SPOT con una antigüedad mayor a cinco años. Por otro lado, el uso de algunos dispositivos que permiten la captura de la información desde el aire se ha extendido ampliamente más allá de las prácticas militares. Es posible trazar la creciente promoción de los drones como un dispositivo “inofensivo" y potencialmente aplicable en usos civiles que comprenden 
desde el transporte de mercancías, la ayuda humanitaria, el monitoreo de cultivos, la cobertura periodística de eventos, la vigilancia en áreas de frontera hasta la producción de fotografías y videos no profesionales ${ }^{4}$. Una investigación de mercado realizada en el año 2015 ofrece algunas claves para entender las razones de la promoción de los usos no bélicos de los drones: se estima que el mercado global de drones se triplicará en la próxima década debido al crecimiento de su aplicación en prácticas recreativas y comerciales $^{5}$.

Los récords de ventas de libros con imágenes aéreas, la proliferación de sitios de Internet que comercializan las imágenes tomadas desde drones y de otros en los cuales ellas se exponen tales como Dronestragram o Games of drones son tan solo algunos de los indicios del renovado interés que despierta la visión aérea ${ }^{6}$. En sitios como Dronestagram, por ejemplo, los miembros de una comunidad virtual comparten las imágenes logradas y recomendaciones sobre cómo obtenerlas o lidiar con los problemas técnicos que suelen suscitarse. Siguiendo la práctica de las redes sociales los usuarios likean $\mathrm{y}$ comentan las imágenes compartidas ${ }^{7}$. El sitio asemeja la visión que ofrecen estas imágenes a la de un pájaro y con un sugerente título postula el nacimiento de un nuevo lenguaje fotográfico ${ }^{8}$. Empero, este modo de mirar no resulta novedoso en la historia de la visión; tampoco en la historia de la creación de vistas aéreas con la imaginación. Podríamos, entonces, comenzar a revisar el estatuto de novedad asignado a este modo de ver que en principio estaría definido por una distancia entre el objeto fotografiado y los dispositivos de captura de la información lo suficientemente lejana para lograr una perspectiva vertical $\mathrm{u}$ horizontal y a la vez lo suficientemente próxima como para permitir el reconocimiento de los objetos.

Algunas obras literarias $\mathrm{y}$ registros gráficos, como los mapas a vista de pájaro, dan cuenta que la facultad de imaginar vistas aéreas (y el deseo que la activaría) precedió la experiencia directa de ver desde el aire. El geógrafo Denis Cosgrove y el fotógrafo William Fox (2010) identifican una serie de imágenes cuya creación anticipó la propia experiencia de la visión aérea. Una de ellas es el fragmento del mural de la ciudad neolítica Catalhöyük en Turquía con un diseño que simultáneamente expone una vista vertical y una horizontal. Probablemente la doble visión que brinda aquella imagen explica que haya sido caracterizada como un mapa y también como la vista de un paisaje: una serie de cuadrados que se corresponden bastante 
con el patrón de las casas y calles encontrados en las excavaciones se combina con una vista de dos volcanes situados a unos $100 \mathrm{kms}$. Cosgrove y Fox señalan que más allá de la sorprendente correspondencia entre el mural y lo que se encontró en las excavaciones, tal vez lo más interesante sea que las personas que vivían en aquella ciudad 8000 años atrás pudieron imaginar y crear un modelo gráfico de lo que se podría ver desde un punto de vista aéreo (también imaginario). Se han encontrado otras imágenes de este tipo en el arte egipcio, chino y persa y esto sugiere que la habilidad de imaginar y la capacidad creativa de dibujar cómo se vería desde arriba, sin haberlo experimentado con los propios ojos, no fue exclusiva de una sociedad. Un poco más cercanas temporalmente, algunas pinturas de principios del siglo XIV ofrecen vistas oblicuas y verticales. Las pinturas de Leonardo da Vinci, particularmente el plano de Imola de 1502, dan cuenta del grado de desarrollo y sofisticación que, precediendo a la experiencia visual aérea, había alcanzado la imaginación.

La experiencia de volar y ver de manera directa desde el aire es cada vez más frecuente en nuestras sociedades. $\mathrm{Si}$ esto no fuera suficiente, incluso antes de la escolarización, nos acercamos a este punto de vista a través de ilustraciones en libros orientados específicamente al público infantil $^{9}$. En nuestra vida cotidiana, en cuestión de instantes, una serie de aplicaciones disponibles en tabletas o teléfonos inteligentes exponen ante nuestros ojos una perspectiva que simula la experiencia de alejarnos de la Tierra (y verla) a una distancia próxima a los 25000 $\mathrm{km}$ de altitud y aproximarnos a distancias que varían entre 1 y 15 metros.

Las imágenes aéreas forman parte de nuestra cultura visual. Sabemos que su producción comprende un complejo y extenso proceso desde la propia producción del conjunto de objetos que interviene en la captura y tratamiento de la información (programas, ordenadores, técnicos), la aplicación de conocimientos relativos a los principios y leyes del espectro electromagnético, al comportamiento espectral de distintos objetos y superficies así como en el conjunto de decisiones que incide directamente en lo que vemos. Dicho de otro modo, conocemos y compartimos un conjunto de convenciones que nos llevan a reconocer o identificar en las imágenes aquello que en algunos casos no podríamos ver a partir de la observación directa (por ejemplo la posibilidad de observar un mismo fenómeno en distintas bandas del espectro electromagnético) y 
en otros, percibiríamos de manera diferente.

Las imágenes aéreas también participan en la configuración de nuestros imaginarios geográficos. En distintos momentos históricos, algunos pintores, fascinados con la visión aérea, apelaron a imaginar el territorio desde esa perspectiva para crear imágenes y para ello se valieron de las imágenes aéreas que habían visto y que de algún modo fueron fijándose en su memoria visual. Entre ellos, Kazimir Malévich y otros artistas del suprematismo que se han utilizado la perspectiva aérea en sus pinturas para transformar los objetos en su configuración geométrica (Lodder, 2013). La visión aérea, ya experiencia directa de ver desde el aire o como interpretación de la transcripción gráfica de esa experiencia, despliega nuevas posibilidades cognitivas al ofrecer otros modos de ver el territorio (Weems, 2015). Si aceptamos que la visión aérea constituye un modo particular de pensar el territorio, podríamos sugerir que la creciente ubicuidad de las imágenes aéreas en nuestra contemporaneidad interviene en los modos de entender e imaginar la información geográfica de públicos cada vez más amplios sin restringirse exclusivamente a los equipos de técnicos y especialistas. Resulta pertinente entonces interrogar qué es lo que nos da a ver una imagen capturada desde un punto más alto, ya sea desde un globo aerostático, un avión, un satélite o un drone. Tal vez este interrogante nos permita desentrañar la renovada fascinación que experimentamos ante las imágenes aéreas.

\section{Los atributos de una visión cada vez más deseada}

Desde finales del siglo XVIII esta forma emblemática de visión de la modernidad (Dorrian y Pousin, 2013) ha estado ineludiblemente ligada al desarrollo de las tecnologías de movilidad aérea tales como los globos aerostáticos, los aviones, y más recientemente los satélites y los drones (Cosgrove y Fox, 2010). La verticalidad y el alejamiento del punto de observación definen un modo de ver, caracterizado por un conjunto de características singulares, con notables implicancias en la percepción, conocimiento, imaginación, ordenación y gestión del territorio. Este modo de visión fue tempranamente valorizado por los Estados, particularmente en sus prácticas militares. No obstante, existen evidencias que la visión aérea también fue incorporada con prontitud en prácticas y discursos de la esfera civil ${ }^{10}$. En efecto, son numerosas las prácticas que en el 
campo civil se han beneficiado de la potencia sinóptica de la visión aérea, entre ellas mencionaremos tan solo algunas como la identificación e interpretación de sitios arqueológicos, la evaluación de usos del suelo y de actividades agrícolas, el estudio y la evaluación de la escala del impacto de eventos de diversa naturaleza, más recientemente la vigilancia y el control de los flujos de personas y bienes en áreas de frontera (Arteaga Botello, 2016).

La verticalidad y el alejamiento de la superficie terrestre supone, en primer lugar, un cambio de la escala de observación y una ampliación del campo de visión. Se extiende el área bajo observación y la visión se emancipa de ciertos límites topográficos o de las barreras físicas que se interponen en la perspectiva horizontal. De este modo, la visión aérea ofrece la promesa y la ilusión de ver todo $\mathrm{y}$, desde esa posición privilegiada, el control y el dominio (no solo visual) del territorio. Los estudios poscoloniales han demostrado que no es casual el estrecho vínculo existente entre la emergencia de las tecnologías de visión aérea y la expansión imperial y colonial; tampoco que su notable desarrollo esté ligado a su aplicación como tecnología de guerra (Adey, 2010).
El distanciamiento y la verticalidad invisibilizan ciertos detalles e intervienen en la percepción de los objetos como formas simples y simétricas. De manera análoga al arte minimalista, este punto de vista supone eliminar "todo detalle para imponer objetos comprendidos como totalidades indivisibles [...] todos $\sin$ partes” (Didí-Huberman, 2006:30). Y sigue: "El resultado de tamaña eliminación del detalle -incluso de toda parte composicional o relacional- habrá sido entonces proponer objetos de formas excesivamente simples, generalmente simétricos, objetos reducidos a la forma mínima $[\ldots .$.$] a la sola formalidad de su$ forma, a la sola visibilidad de su configuración visible, ofrecida sin misterio, entre línea y plano, superficie y volumen” (Didí- Huberman, 2006: 30/31). Probablemente por ello la visión aérea haya sido escogida por los arquitectos modernistas en la planificación urbana para reconstruir ciudades y recrearlas como patrones geométricos. La simplicidad de las formas, componente estético de los registros visuales aéreos, también nos permite entender el placer que todavía suscitan las imágenes aéreas. Los aportes de la psicología cognitiva señalan que cuando vemos un objeto solo podemos percibirlo si logramos colocarlo o referenciarlo a una forma arquetípica 
(Arnheim, 1997). La percepción de la forma es un elemento estructurante del pensamiento en tanto ofrece un grado de generalidad que permite ser aplicado a más de un objeto y puede ser reconocido con relativa facilidad.

No obstante y más allá del placer estético, la supresión de los detalles y la ampliación del campo de visión promueve una modalidad de visión muy apreciada en el mundo contemporáneo, particularmente en el análisis de datos (Halpern, 2014). Se trata situar la información visual en relación, en series o secuencias como puntapié para la identificación de patrones. La visión sinóptica hace visible fenómenos o procesos que tal vez podríamos llegar a intuir/ vislumbrar con nuestra imaginación. Dicho de otro modo, la visión aérea constituye una forma de pensar y entender el territorio: da visibilidad a un orden de formas, patrones y relaciones no siempre susceptibles de reconocimiento e identificación desde la superficie y de este modo otorga entidad a ciertos fenómenos (Castro, 2013: 132).

Ver desde el aire también ha provocado cierto desconcierto y un efecto de extrañamiento: lo conocido se presenta bajo otro aspecto, forma, textura, color, tamaño y como consecuencia se vuelve extraño o desconocido. La búsqueda de tornar inteligible lo visto desde el aire y vencer este extrañamiento se ha materializado en diferentes aproximaciones de registro gráfico que han resultado en la producción de varios tipos de imágenes. A fines analíticos y tomando como criterio básico las características de la imagen obtenida así como los dispositivos técnicos que han intervenido en su producción ${ }^{11}$ se podría establecer una tipología de cuatro grupos primarios de imágenes aéreas: dibujos/bosquejos (fines del siglo XVIII), fotografía (desde fines de la década de 1850), imagen móvil (desde la segunda década del siglo $\mathrm{XX}$ ) e imagen satelital (desde fines de la década de 1950).

La historia de los registros gráficos producidos en torno a la experiencia aérea nos enfrenta a imágenes que ofrecen una visión cada vez más realista y en las cuales incluso se borra su carácter de transcripción. Sin embargo, la producción de cada uno de estos registros entraña un conjunto de operaciones de intervención, recorte, selección, inclusión y exclusión. En los dibujos/bosquejos esta producción se expone de modo más evidente ante quien mira: el trazado gráfico da cuenta del esfuerzo de memorizar aquello que se ha visto $\mathrm{y}$ luego, transcribirlo gráficamente a un papel. El proceso de producción de los otros tres registros, en cambio, se vuelve más difuso. La 
fotografía, la imagen aérea móvil y la imagen satelital comparten la existencia un dispositivo - la cámara o el sensor- que opera como memoria y resulta luego en una transcripción del campo de visión. El dispositivo por un lado, permite captar y registrar detalles que podrían escapar al ojo desnudo y a la memoria; por otro lado, difiere la temporalidad de la mirada e incluso otorga la posibilidad de repetir el acto de ver así como de efectuar comparaciones con otras imágenes tomadas en diferentes momentos históricos o en otros sitios.

La innovación tecnológica de las últimas dos décadas en el campo de la aviación ha privilegiado el desarrollo de los drones, dispositivos de movilidad aérea cada vez más portátiles (y de menor costo), con mayor autonomía de vuelo y más estabilidad así como la incorporación de más cámaras de mejor calidad y con mayor conectividad. Las cámaras como dispositivos también han ido ganando autonomía hasta desprenderse de la necesidad de un sujeto que active un disparador para la obtención de la imagen. Todavía más: los dispositivos mecánicos han sido reemplazados por sensores digitales que ya no requieren de una superficie sensible para grabar la información obtenida $\mathrm{y}$ esto a su vez posibilita el tratamiento digital de las imágenes, el acceso inmediato y desde puntos remotos a la información visual, una mayor circulación y su reproducción en distintos soportes. Este conjunto de avances ofrece mayor libertad para fotografiar o filmar y prometen la obtención de mejores imágenes aéreas, es decir, la producción de imágenes todavía más realistas.

\section{Sobrevuelos de hiper-realismo}

George Didí- Huberman, en el libro Ante el tiempo. Historia del arte $y$ anacronismo de las imágenes, propone pensar la imagen como portadora de memoria: "En la imagen chocan y se desparraman todos los tiempos con los cuales está hecha la historia”. En las imágenes aéreas se recrea el deseo ancestral de ver todo (panóptico), en particular aquello que no podríamos ver con nuestros ojos de manera directa, aquello inaccesible por motivos tan diversos como los límites que impone nuestra propia corporalidad hasta los que introducen otras variables tan fortuitas como las condiciones atmosféricas. Una recorrida rápida por los sitios en las cuales se exponen imágenes tomadas desde drones permite constatar que, a modo de postales turísticas, exponen lugares que, aún desde otro punto de vista, ya forman 
parte de nuestra memoria visual. En estas imágenes además de recrear aquel deseo de extender la mirada más allá de lo que nuestra visión directa permitiría, se reeditan las imágenes (y lo que ellas nos dan a ver) que ya hemos visto, se han grabado en nuestra memoria visual $y$ han moldeando nuestros imaginarios geográficos ${ }^{12}$.

Algunas imágenes aéreas presentan ciertos trazos a partir de los cuales es posible reconocer que estamos ante una filmación o ante una fotografía el movimiento de la cámara, la inestabilidad del propio drone, la falta de nitidez o menor calidad en la imagen, el sonido del dispositivo en vuelo o las huellas del propio montaje. Ya sea por la menor destreza de quien dirigió el dispositivo de vuelo o por el menor grado de sofisticación de la/s cámaras y del drone propiamente dicho en algunas imágenes todavía encontramos en ellas trazos notables de su construcción. Sin embargo, este tipo de imágenes no son las de circulación más frecuente en Internet. Las imágenes con mayor número de visualizaciones constituyen "el sueño visual de la cosa misma” (DidíHuberman, 2006: 32).

Son imágenes que, como los mapas, nos acercan puntos de vista que difícilmente podríamos tener de manera directa. Pero la verosimilitud y efectividad de las imágenes obtenidas desde drones se construye en una arquitectura visual que hace que las miremos como lo real: la intensidad de los colores, la alta definición, el diálogo del punto de vista oblicuo con el vertical (que nos permite reconocer los objetos desde la perspectiva oblicua antecediendo o siguiendo a la perspectiva vertical) sutilmente trazado en una trayectoria de vuelo confluyen en hacernos sentir y creer que estamos en ese viaje. El hiper-realismo de estas imágenes también se apoya en los objetos involucrados en su producción. En efecto, el drone y las cámaras, en tanto objetos técnicos, se conciben como más objetivos que el ojo humano y atribuyen así un estatuto de registro objetivo $\mathrm{y}$ fiel a las imágenes resultantes. Finalmente, el hecho de que la visión aérea sea parte de nuestra cultura visual interviene en la calidad de las imágenes logradas y en el estatuto que ellas toman. Ya en 1931 André Cholley relacionaba la efectividad de las imágenes aéreas a la experticia del fotógrafo y su conocimiento geográfico para seleccionar el ángulo y el punto de vista más adecuado para cada paisaje (Robic, 2013). Un mayor entrenamiento en habilidades como el manejo de los dispositivos en cuestión, la imaginación y la visión aérea resultan en imágenes con 
características que promueven la naturalización de todo el conjunto de procedimientos, decisiones y selecciones que las definen como tales.

La innovación de algunos drones promete hacernos sentir la inmersión en una experiencia de vuelo sin la condición de subirnos a un avión o a otro dispositivo de aviación. Para ello bastaría colocarnos una especie de lentes que permiten seguir el vuelo del drone con nuestros ojos y tener un campo de visión de 85 grados de amplitud. Ver ya no solo atravesaría los ojos sino también toda nuestra corporalidad aún sin estar físicamente en un objeto que nos permita hacerlo ${ }^{13}$.

Estos nuevos lentes mágicos nos recuerdan otros con los cuales se intentó dar volumen a las imágenes para el entretenimiento de masas con gran éxito durante la segunda mitad del siglo XIX y comienzos del siglo XX. Baudelaire hablaba de "juguete científico" para referirse al estereoscopio en virtud de la atracción y el gusto que despertaba la experiencia de ver en tres dimensiones. Sin embargo, el volumen no se crea en el aparato: nuestros ojos nunca recorren la imagen en una completa aprehensión de la tridimensionalidad de la totalidad del campo, sino en términos de una experiencia localizada de áreas separadas (Iturriaga, 2013: 30). El estereoscopio
“[ $[.$.$] dispone de tal modo del sujeto que$ cae en su trampa, que uno llegaría a olvidar que en el estereoscopio (tal como lo decía Leonardo da Vinci de la imagen en el espejo) sólo hay una imagen para el que mira” (Damish, 2007: 39). Jonathan Crary (2008) discute que el estereoscopio otorgó un rol fundamental al sujeto en tanto "productor de verosimilitud". Es el sujeto que mira quien restituye ese mosaico al mirar, aunque en el siglo XIX $\mathrm{y}$ comienzos del XX este poder se atribuyera al estereoscopio.

De manera análoga al estereoscopio, estos “nuevos" lentes aíslan de la realidad mediata a quien se los coloca y lo fuerzan a mirar solo lo que la(s) cámara(s) del drone capturan. A tal punto la imagen es para que el que mira que una firma de drones comercializa dos pares de lentes para que sea posible compartir esa experiencia de visión y de vuelo virtual simultáneamente con otra persona. $\mathrm{Si}$ asumimos como cierta la tesis de Crary sobre las imágenes estereoscópicas, podríamos sugerir que las fotografías $\mathrm{y}$ videos tomados desde drones, en cambio, anclan su verosimilitud en su realismo y en la objetividad de los aparatos (drones, cámaras y lentes). Las imágenes aéreas contemporáneas, principalmente aquellas producidas con drones, ofrecen indicios de que volvemos a atravesar un período en el 
cual el poder de las imágenes pareciera anclarse en su realismo. Podríamos comenzar a interrogarnos cómo desmontar el realismo de estas imágenes con la finalidad de "inquietar el ver, en su acto, en su sujeto" (Didí-Huberman, 2006:47). La obra del artista Josh Begley y los trabajos del historiador del arte George Didí-Huberman brindan algunas pistas para comenzar a desmontar el realismo de estas imágenes y a la vez construir una metodología de trabajo con ellas desde la idea de composición.

\section{La composición como método para inquietar la mirada}

Fatal migrations 2001-2016 es una de las obras de Josh Begley, un artista estadounidense que toma Internet como el soporte físico para desarrollar y exponer sus obras ${ }^{14}$. Se trata de una composición de imágenes aéreas fijas, todas ellas tomadas de Google Earth, dispuestas en filas y columnas ${ }^{15}$. Una vez que se ingresa al sitio de Internet se empiezan a desplegar paulatinamente círculos distribuidos en un número interminable de columnas y filas con un perímetro negro que enmascara cada círculo y que evoca el recorte visual que tendríamos al mirar con la lente de un microscopio o de un telescopio. La homogeneidad en la trama visual se interrumpe eventualmente con algunos círculos, con un tono más suave que la máscara, que contienen la inscripción de la palabra Unknown (desconocido). La composición ofrece simultáneamente una visión macroscópica - dada por la perspectiva aérea y la distancia existente entre el punto de toma de la imagen y los objetos, en la cual los objetos se perciben como formas simples y simétricas- y microscópica - configurada por la posibilidad de aproximación que se despliega al hacer click en cada círculo: como si nuestros ojos se dispusieran ante un instrumento óptico que amplía la imagen de los objetos y nos aproxima a los detalles.

El título de la obra es elocuente para imaginar qué es lo que cada una de las imágenes desplegada en esos círculos está haciendo presente. También el título funciona como una advertencia: los nombres que figuran en cada uno de los círculos se refieren a los inmigrantes que han muerto al intentar atravesar una frontera. La disposición de las imágenes de la obra acaso trae reminiscencias de los memoriales construidos en diversos lugares del mundo para visibilizar aquellos procesos que han provocado víctimas en masa.

El primer efecto surge del propio dispositivo elegido para la obra. Para Josh 
Begley Internet es la superficie de inscripción de sus composiciones de imágenes. Sería la "mesa para reunir la fragmentación del mundo" (DidíHuberman, 2013: 43). Internet no funciona tan sólo como un lugar de visualización y difusión, sino que interviene directamente en características particulares que toma su obra. En Fatal migrations, la información visual emerge paulatinamente emulando lo que ocurre al descargar un archivo con demasiada información: las filas de círculos se tornan interminables y provocan una mezcla de ansiedad y curiosidad. La temporalidad que impone el soporte en la aparición de las imágenes provoca y renueva la sensación de que el acto de ver todas esas imágenes nunca terminará. Por el contrario, se tornará un proceso tan continuo como inaprensible. Así, el soporte y la composición discuten con efectividad la temporalidad cerrada del título de la obra.

A medida que comenzamos a recorrer los círculos con el cursor aparece un pequeño recuadro en cada uno de ellos. $\mathrm{El}$ breve texto (solo visible si apoyamos el cursor en el círculo) vincula cada imagen aérea a un nombre propio y a una fecha precisa. La composición de Begley revela que no existe un orden cronológico en la disposición de las imágenes tanto en las filas como en las columnas. Esta dispersión o desorden cronológico es parte de la obra. Por un lado, señala la complejidad que ha entrañado reconstruir esos datos; por otro, ofrece itinerarios múltiples que complejizan la temporalidad del acto de mirar.

Ya hemos dicho que si el cursor (y nuestros ojos) se detiene en cada círculo se despliega un texto tan breve como potente en la composición integrado por un nombre propio y una fecha que, a partir del título de la obra, ineludiblemente interpretaremos como las fechas de deceso de esos migrantes. El texto hace que la distancia que supone la perspectiva aérea se re-configure: la imagen nos trae el lugar de la muerte de un migrante. La obra y el soporte permite "aproximarnos" a un lugar como si nos acercáramos a la lente de un microscopio: comenzamos a ver con más detalles la vegetación, los caminos, las casas. La imagen con ese texto y en esa composición otorga proximidad a la visión aérea. Estas imágenes, a diferencia de las que exponen los medios de comunicación y redes sociales, no muestran los rostros ni los cuerpos de quienes buscan atravesar la frontera. Exponen, en cambio, su ausencia en un lugar preciso aunque no exista ninguna clave precisa para que lo identifiquemos. 
En otros círculos aparece alternativamente un nombre o una fecha combinado con la palabra Unknown. La aproximación visual nos permite identificar los detalles de ese lugar y a la vez nos confronta ante lo que la imagen, a pesar de todo lo que expone, nos presenta como lo desconocido. El vacío se acrecienta todavía más en los círculos negros dado que en nuestra cultura visual este color remite al luto ante la pérdida de una vida humana. Esos círculos negros (que al apoyar el cursor se vuelven cuadrados negros de la dimensión de la pantalla de la computadora) hacen visible lo que se desconoce, aquello que se ignora de estas migraciones mortales ya sea el lugar, el nombre de las personas y en algunos, ambos datos. Paradójicamente, esto que se desconoce opera como aquello que nos hace conocer. Cada uno de estos fragmentos de la imagen aérea muestra y a la vez se revela incompetente e incompleta en tanto siempre deja un vacío en un nombre, en una fecha o en un lugar. Poco importa si la imagen aérea corresponde exactamente o no al lugar en el que cada una de estas migraciones se convirtió en fatal. La decisión del artista de no incluir el nombre del lugar nos fuerza a salir del registro de lo real, y a pesar de ello nos coloca en ese lugar preciso, en una historia personal interrumpida y en esos lugares en tanto composición que hace visible la recurrencia de algunos patrones: líneas como tajo y fracturas que atraviesan algún fragmento de la imagen.

Tres aspectos de esta obra de Josh Begley nos remiten a las contribuciones de Didí-Huberman y nos permiten pensar un método en el trabajo con las imágenes, particularmente en un contexto de sobreabundancia de imágenes. En primer lugar, la obra de Begley es una composición realizada con una enorme cantidad de imágenes ${ }^{16}$. Begley deliberadamente trabaja con imágenes de dominio público que de por sí ya tienen gran circulación y por tanto no resultan tan extrañas para los no especialistas. Sin embargo, su obra propone una composición bien diferente a la que presenta Google Earth, aunque se trate exactamente de las mismas imágenes que podríamos encontrar allí. Begley compone otro orden, otra secuencia y así también otra argumentación para esas imágenes. En Fatal migrations, Josh Begley nos ofrece otra re-lectura de las migraciones y con ella otra re-lectura del mundo contemporáneo (Didí-Huberman, 2013: 20). Esta composición no expone rostros ni cuerpos fatigados, doloridos, quebrados, abandonados. Empero, el trabajo de montar esta composición realizado por 
Begley nos hace imaginar cada una de esas historias y simultáneamente las conecta en una trama que trasciende las historias personales. La obra nos exige seguir mirando a pesar del cansancio suscitado ante la monotonía visual de esas filas y columnas y de nuestra negación a involucrarnos ante el dolor de otros.

En segundo lugar, Begley estructura la composición disponiendo las imágenes de manera adyacente en una especie de panel que permite, como explica Edward Tufte, mostrar simultáneamente repetición y cambio, patrón y sorpresa. A su vez la constancia en algunos elementos del diseño, como la máscara en color negro, nos orienta a concentrar nuestra mirada en la información visual que se despliega, en los cambios y en las recurrencias. La multiplicidad de las imágenes y su adyacencia intensifica y refuerza el significado de las imágenes (Tufte, 1997: 105) y de este modo contribuye a la identificación y evaluación rápida de cambios, la patrones, contrastes y correspondencias. Dicho de otro modo, la disposición adyacente en filas $\mathrm{y}$ columnas de cada una de esas imágenes cuidadosamente seleccionadas hace que cada una de las historias de migración fatal se entienda como un proceso social.

Finalmente, esta obra expone los límites de la imagen y la potencialidad del trabajo de componer montajes o series con ellas: las imágenes ya no solo funcionarían por su alianza con las palabras sino que lo harían en tanto elementos integrantes de una composición. Para George DidíHuberman el trabajo de composición de series de imágenes y proponer otros órdenes para ellas supone desplazarlas a otro nivel de inteligibilidad $y$ de legibilidad (Didí- Huberman, 2008: 41). El montaje permite entrever, establecer relaciones cuyo vínculo no es evidente: "Adjuntar visual y temporalmente, diferencias". [...] Distanciar es saber manipular el material visual y narrativo" (Didí- Huberman, 2008: 78). Una tarea que, como analiza rigurosamente DidíHuberman en sus investigaciones tiene una larga tradición como método de trabajo con las imágenes ${ }^{17}$, se presenta todavía más necesaria ante un universo visual que no deja de expandirse. En Fatal migrations, la composición hace que un conjunto de imágenes satelitales, generalmente categorizadas como técnicas por excelencia, se re-configuren y ofrezcan otras miradas de la frontera. La obra de Begley evidencia que incluso aquellas imágenes que nos proponen un modo de visión históricamente enlazado al poder a través de prácticas militares, utilizado habitualmente para el control y la vigilancia en las áreas de frontera, pueden 
ofrecer de modo efectivo, a través de un trabajo de composición, otras narrativas de la frontera.

\section{Los límites y las potencias de las imágenes (aéreas)}

La difusión y mayor grado de sofisticación de las cámaras voladoras, sin duda, emancipa nuestra visión de cierto tipo de restricciones físicas, pero pareciera reforzar otras restricciones de modo similar a lo que les ocurría a los primeros viajeros aéreos: desde los globos conseguían mirar el mundo desde el aire, experimentar una nueva perspectiva visual pero por mucho tiempo no encontraban las formas para transcribir esa experiencia (Thébaud-Sorger, 2013: 46). La reciente y creciente ubicuidad de las cámaras voladoras interviene para que consigamos extender nuestra mirada $y$ hacerla más refinada y precisa sin necesidad de volar. La ubicuidad de las imágenes aéreas hace que dispongamos de más transcripciones ( $\mathrm{y}$ no registros) de esa visión. En otras palabras, ya tenemos las transcripciones pero no las reconocemos como tales. La obra de Begley nos permite reconocer el carácter problemático de las imágenes aéreas como transcripciones de una experiencia visual. Su obra disloca el poder de las imágenes aéreas al menos en tres sentidos: expone lo que no podemos ver con la visión aérea (el vacío), elude la esperada correspondencia entre la imagen y una localización precisa y finalmente construye el poder de la imagen aérea no en su individualidad sino en su diálogo con otras imágenes.

Sabemos que las imágenes aéreas invisibilizan ciertos detalles e intervienen en la percepción de los objetos como formas simples y simétricas. Fatal migrations nos hace experimentar los límites de la imagen aérea. La composición de Begley expone lo que no podemos ver con la visión aérea: el vacío, lo que desconocemos, en definitiva los límites de toda imagen. El límite, siguiendo el análisis de Didí- Huberman, puede convertirse en más de lo que se espera, puede perturbar la mirada, provocar la pregunta. Ese límite, eso no visible, ese vacío es precisamente lo que nos permite imaginar.

El cineasta Jean-Luc Godard decía que no hay imagen, sino que solo hay imágenes, en plural. La obra de Begley precisamente construye su potencia en en ese diálogo entre las imágenes. Es en ese plural que las imágenes satelitales de la obra de Begley activan la imaginación también para quien la mira: la imaginación entendida como una facultad que percibe 
las relaciones íntimas de las cosas, las correspondencias y las analogías (DidíHuberman, 2011: 177). Asímismo, es ese diálogo visual que se produce al componer y mirar estas composiciones que constituye un acto político. La obra de Begley no nos muestra de manera directa el desgarro de los inmigrantes pasando las fronteras. En cambio, su composición nos presenta una reconstrucción de ese desgarro y de ese horror.

Tal vez en este período de mayor producción y circulación de imágenes deberíamos empeñarnos más en identificar, analizar y mostrar las diferencias, las polifonías, lo múltiple de una cultura visual que pareciera presentarse cada día como más homogénea. Creo que, como Begley, somos capaces de proponer montajes potentes, inquietantes que movilicen nuestros imaginarios geográficos y nos hagan sentir que no podemos renunciar a mirarlos porque nos permiten entrever, re-leer y posicionarnos ante estos archivos visuales del mundo cada vez más inaprensibles, cada vez más desgarradores y cada vez más necesarios para interpretar y tomar posición en este mundo tan complejo como babélico.
NOTAS

* Doutora em Ciências Sociais (FLACSO- Buenos Aires). Master of Arts in Human Geography (University of British Columbia- Canadá). Graduada em Geografía (Universidad Nacional del Comahue). Atualmente é Pesquisadora Adjunta do CONICET na Universidade de Buenos Aires e professora na Universidad del Centro de la Provincia de Buenos Aires. Seu objeto de pesquisa é a relação entre cultura visual e geografia. Atua como professora de Geografia no ensino secundário (na rede particular e pública de ensino) e na escola de capacitação de professores na cidade de Buenos Aires.

vhollman@conicet.gov.ar

1 El programa Landsat de la National Aeronautics and Space Administration (NASA) ha tenido continuidad y sistematicidad en la obtención de información espectral de la superficie terrestre desde su lanzamiento en el año 1972.

2 A partir del año 2008 el United States Geological Survey (USGS) emprendió una política de centralización de las imágenes del programa Landsat obtenidas en estaciones terrestres localizadas fuera de los Estados Unidos a través de la iniciativa denominada Landsat Global Archive Consolidation.

3 Véase https://landsat.usgs.gov/total-landsatdistribution

4 Un representante de la industria aeroespacial israelí (Israel es uno de los principales productores de drones a nivel mundial) sugería la creación de campañas de promoción multidisciplinarias tendientes a que la población conciba y acepte esta tecnología como una "parte natural de la sociedad" (Graham, 2016: 87).

5 Teal Group. "World Unmanned Aerial Vehicle Systems, Market Profile and Forecast 2015" 
${ }^{6}$ El éxito de la exposición La Tierra vista desde el cielo, presentada en espacios públicos de más de cien ciudades, con patrocinio de la UNESCO y dirección del reconocido fotógrafo francés Yann Arthus-Bertrand, así de series de libros de fotografías aéreas confirma el renovado interés que despierta el modo de visión que nos acercan estas imágenes.

${ }^{7}$ El espectáculo visual se formalizó en un concurso internacional de fotografías tomadas desde drones que, con patrocinio de National Geographic, ya tuvo su tercera edición.

8 Véase http://www.dronestagr.am

9 Agradezco a la Doctora Malena Mazzitelli Mastricchio esta observación y las vistas aéreas presentes en libros para niños que me hizo conocer.

${ }^{10}$ Denis Cosgrove y William Fox (2010: 29) citan la publicación de un libro en 1886 en el cual se identifica una multiplicidad de posibles usos de la fotografía aérea en el campo civil.

11 El dispositivo de movilidad aérea así como el tipo de dispositivo de captura interviene en las características de la imagen y también en lo que ésta hace visible o no.

12 El relato del autor de una de las obras premiadas en la tercera edición del concurso de fotografía con drones es elocuente: explica que desde el día que vio una fotografía aérea en la cual las puntas de los edificios del centro de una ciudad sobresalían en el medio de una espesa niebla sintió el deseo de hacer una imagen similar de su ciudad hasta lograrlo con la fotografía premiada.

${ }^{13}$ No es casual que la edición de gran parte de los videos realizados con drones consista en colocar una música "apropiada” para las imágenes, reforzando de este modo aún más la centralidad de la visión en la experiencia virtual de vuelo.
14 Josh Begley tomó más notoriedad por desarrollar una aplicación para Iphone (que la empresa rechazó varias veces aduciendo que se trataba de una aplicación con contenido cuestionable) en la que cada vez que un drone de Estados Unidos ataca en Pakistán, Yemen o Somalia se despliega una notificación. Sus obras pueden encontrarse en: https://joshbegley.com

15 Por lo general Begley organiza la composición de las imágenes fijas en una disposición de filas y columnas. Las imágenes se despliegan de modo adyacentes y son múltiples. Entre ellas: Officer involved una serie de fotografías tomadas de Google maps que visibiliza los lugares en los que la policía asesinó personas, Prision map otra composición de imágenes aéreas (5300 imágenes) que busca trazar la geografía de las prisiones en Estados Unidos, empire.is también es una composición de imágenes aéreas de emplazamientos militares.

${ }^{16}$ Las obras de Begley se enlazan a un conjunto de obras artísticas creadas tomando como base el Big Data, esa enorme cantidad de datos globales generados a partir del uso de Internet, redes sociales, teléfonos inteligentes y tantas otras aplicaciones que se almacena digitalmente. Las imágenes del territorio también hoy forman parte del Big Data.

${ }^{17}$ La composición como método de trabajo con las imágenes y de re-lectura del mundo se remonta para Didí-Huberman a la mesa de trabajo del historiador de arte alemán Aby Warburg y de su Atlas Mnemosyne con 60 láminas de imágenes que rastrean la pervivencia de símbolos y arquetipos que migran desde la antigüedad.

\section{REFERÊNCIAS BIBLIOGRÁFICAS}

ADEY, P. (2010). Aerial life. Spaces, mobilities, affects. Oxford: Wiley-Blackwell Publishing, Inc. 
ARNHEIM, R. (1997). Visual thinking. Berkeley: University of California Press.

ARTEAGA BOtello, N. (2016). Política de la verticalidad: drones, territorio y población en América Latina. In: Región y Sociedad, 65, 263-292.

CASTRO, T. (2013). Aerial views and cinematism, 1898-1939. In M. Dorrian \& F. Pousin (Eds.), Seeing from above. The aerial view in visual culture (pp. 118-133). London and New York: I.B.Tauris.

COSGROVE, D., \& WILliAM, F. (2010). Photography and Flight. London: Reaktion Books.

CRARY, J. (2008). Las técnicas del observador. Visión y modernidad en el siglo XIX. Murcia: CENDEAC.

DAMISCH H. (2007). El desnivel. La fotografía puesta a prueba. Buenos Aires: La Marca Editora.

DIDÍ-HUBERMAN, G. (2006). Lo que vemos, lo que nos mira. Buenos Aires: Manantial.

DIDÍ-HUBERMAN, G. (2008). Cuando las imágenes toma posición. Madrid: Antonio Machado Libros.

DIDÍ-HUBERMAN, G. (2011). Ante el tiempo. Historia del arte y anacronismo de las imágenes. Buenos Aires: Adriana Hidalgo Editora.

DIDÍ-HUBERMAN, G. (2013). Atlas ou a Gaia Ciência inquieta. Lisboa: KKYM + Escola de Arquitectura, Universidade de Minho.

DORRIAN, M., \& POUSIN, F. (2013). Seeing from above. The aerial view in visual culture. London and New York: I.B.Tauris.

GRAHAM, S. (2016). Vertical. The city from Satellites to Bunkers. London: Verso.
HALPERN, O. (2014). Beautiful data. A History of Vision and Reason since 1945. Durham and London: Duke University Press.

ITURRIAGA, J. (2013). La estereoscopía en la historia. Empoderando al observador y relativizando lo natural. In: Fajnzylber, V.(editor) La imagen táctil. De la fotografía binocular al cine tridimensional. Santiago de Chile: Fondo de Cultura Económica.

LODDER, C. (2013). Transfiguring reality: Suprematism and the aerial view. In: Dorrian M. \& POUSIN, F. (ed) Seeing from above. The aerial view in visual culture (pp. 95-117). London: I.B.Tauris.

ROBIC, M. (2013). From the sky to the ground. The aerial view and the Ideal of the Vue Raisonnée in Geography during the 1920s. In: Dorrian M. \& Pousin, F. (ed) Seeing from above. The aerial view in visual culture (pp. 163-187). London: I.B.Tauris.

THÉBAUD-SORGER, M. (2013).Thomas Baldwin's Airopaidia, or the Aerial View in Colour. In: Dorrian M. \& Pousin, F. (ed) Seeing from above. The aerial view in visual culture (pp. 46- 65). London: I.B.Tauris.

TUFTE, E. (1997). Visual explanations. Images and Quantities, Evidence and Narrative. Connecticut: Graphic Press LLC.

WEEMS, J. (2015). Barnstorming the Praires. How Aerial Vision Shaped the Midwest. Minneapolis: University of Minnesota Press.

WULDER, M. et al. (2016). The global Landst archive: Status, consolidation, and direction. In: Remote Sensing of Environment, 185, 271-283. 


\section{VISÃO AÉrEA E IMAGINÁRIOS GEOGRáFICOS: UMA PROPOSTA DE APROXIMAÇÃO A UM COMPLEXO UNIVERSO VISUAL}

RESUMO: A CONVERGÊNCIA DE UMA CRESCENTE PRODUÇÃO E CIRCULAÇÃO DAS IMAGENS AÉREAS PERMITE QUE UM PÚBLICO

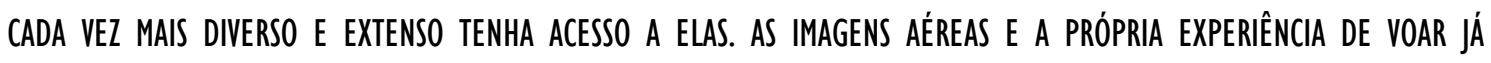

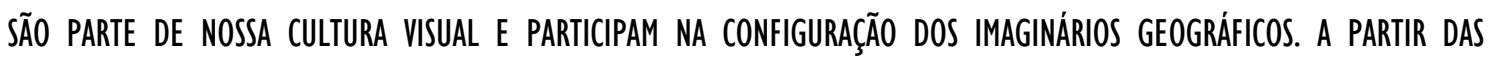
CONTRIBUIÇÕES DE GEORGE DIDÍ-HUBERMAN E DA OBRA DO ARTISTA AMERICANO JOSH BEGLEY PROPOMOS PENSAR AS POSSÍveIS APROXIMAÇÕES A UM UNIVERSO tÃO AMPLO DE IMAGENS QUE SE APRESENTA COMO 0 REAL, EM VIRTUDE DA SUA PRÓPRIA ARQUITECTURA VISUAL E DA SUA PRODUÇÃO.

PALAVRAS CHAVE: VISÃO AÉREA; IMAGENS AÉREAS; TECNOLOGIAS DE VISÃO AÉREA; IMAGINÁRIOS GEOGRÁFICOS; COMPOSIÇÃO

AERIAL VISION AND GEOGRAPHICAL IMAGINATIONS: AN ATTEMPT TO CAPTURE A COMPLEX VISUAL UNIVERSE

ABSTRACT: BOTH THE INCREASING PRODUCTION AND CIRCULATION OF AERIAL IMAGES HAVE CONTRIBUTED tO THE DIFFUSION OF AERIAL VISION TO BROADER AUDIENCES. AERIAL IMAGES AND THE EXPERIENCE OF FLIGHT HAVE BECOME PART OF OUR VISUAL CULTURE. BY AND LARGE, AERIAL IMAGES TURN OUT TO BE MORE REALISTIC AND ARE CONCEIVED AS THE REAL. BY LOOKING AT ONE OF THE ARTISTIC PRODUCTION OF JOSH BEGLEY AND BASED ON THE CONTRIBUTIONS OF GEORGE DIDI-HUBERMAN I AIM TO ANALYZE the COMPOSITION OF IMAGES AS A METHODOLOGICAL APPROACH TO DEAL 
WITH THE IMMENSE UNIVERSE OF AERIAL IMAGES CURRENTLY AVAILABLE AND AT THE SAME TIME UNPACK THE STATUS THEY HAVE ACQUIRED.

KEYWORDS: AERIAL VISION; AERIAL IMAGES; TECHNOLOGIES OF AERIAL VISUALIZATION; GEOGRAPHICAL IMAGINATIONS; COMPOSITIONS. 